\title{
The effect of cardiopulmonary bypass time on renal function after coronary artery bypass grafting
}

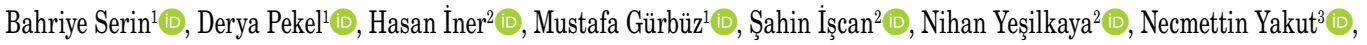 \\ Bortecin Eygi² (D), Yüksel Beşir² (D), Orhan Gökalp² (I) \\ ${ }^{1}$ Perfusion, Institute of Health Science, Izmir Katip Çelebi University, Faculty of Medicine, Izmir, Turkey \\ ${ }^{2}$ Department of Cardiovascular Surgery, Izmir Katip Çelebi University, Faculty of Medicine, Atatürk Training and Research Hospital, Izmir, Turkey \\ ${ }^{3}$ Department of Cardiovascular Surgery, Izmir Akut Heart Hospital, Izmir, Turkey
}

Received: July 14, 2021 Accepted: July 18, 2021 Published online: August 11, 2021

\section{ABSTRACT}

Objectives: In this study, we aimed to evaluate the effect of duration of cardiopulmonary bypass (CPB) on postoperative acute kidney injury (AKI) in patients who underwent coronary artery bypass grafting (CABG).

Patients and methods: A total of 251 patients (222 males, 29 females; mean age: $61 \pm 9.4$ years; range, 37 to 88 years) who underwent elective CABG operation between January 2014 and January 2018 were retrospectively analyzed. The patients were divided into three groups by considering the duration of CPB as 0 to $60 \mathrm{~min}$ (Group 1), 60 to $120 \mathrm{~min}$ (Group 2), and $\geq 120 \mathrm{~min}$ (Group 3). Preoperative, operative, and postoperative data and renal functions of the patients were evaluated using the Acute Kidney Injury Network (AKIN) criteria.

Results: In all three groups, a statistically significant decrease in hemoglobin and estimated glomerular filtration rate (eGFR) values and a statistically significant increase in blood urea nitrogen (BUN) and creatinine values were found ( $\mathrm{p}<0.05)$. In Group 2 and Group 3 , postoperative BUN and creatinine value were significantly higher and eGFR value was significantly lower than Group 1 (p<0.05). In terms of postoperative data, the rate of acute renal failure (ARF) requiring dialysis was significantly higher in Group 2 and Group 3 than Group 1 ( $\mathrm{p}<0.05)$. The postoperative mortality rate was significantly higher in Group 3 than Group $1(\mathrm{p}<0.05)$.

Conclusion: In terms of postoperative mortality and morbidity, it is important to identify the risk factors for AKI and to take appropriate precautions for the risk factors. Minimizing perfusion time in patients undergoing $\mathrm{CPB}$ may help to decrease the incidence of CPB-induced AKI.

Keywords: Acute kidney injury, cardiopulmonary bypass time, coronary artery bypass grafting.

Heart diseases are still the leading causes of death worldwide. The main reason is the mortality related to course of the diseases and surgical practice of these diseases. Cardiovascular surgery has the risk of lung damage, infection, neurological problems, and renal disease. These complications may cause high mortality and morbidity. ${ }^{[1]}$

The kidneys are the most vulnerable organs for cardiopulmonary bypass (CPB). Renal failure, which is a common disease for elderly, is associated with a high mortality rate. Nephrotoxic drugs, cardiogenic shock, major surgical procedures, and intensive care unit (ICU) stay are the main causes of renal failure. ${ }^{[2-4]}$ The most common and important form of renal failure after cardiac surgery is acute kidney injury (AKI). Cardiopulmonary bypass-related non-pulsatile and hypothermic perfusion, and low blood pressure cause hemodilution, decreased renal perfusion, decreased estimated glomerular filtration rate (eGFR), and increased renal vascular resistance. The increase of renal vascular resistance causes the increase of angiotensin II secretion and, consequently, renal blood perfusion decreases. Decreased renal perfusion also increases the release of oxygen radicals. Embolic materials related to aggregated platelets and damaged erythrocyte cells cause the occlusion of renal tubules. All these problems increase the risk of postoperative

Corresponding author: Şahin İşcan, MD. İzmir Katip Çelebi Üniversitesi Tip Fakültesi Atatürk Eğitim ve Araștırma Hastanesi Kalp ve Damar Cerrahisi Kliniği, 35360 Karabağlar, İzmir, Türkiye.

Tel: +90 505 - 4882090 e-mail: sahiniscan@hotmail.com

\section{Citation:}

Serin B, Pekel D, İner H, Gürbüz M, İșcan Ş, Yeşilkaya N, et al. The effect of cardiopulmonary bypass time on renal function after coronary artery bypass grafting. Cardiovasc Surg Int 2021;8(2):78-85. 
AKI. ${ }^{[5]}$ It is important to investigate the negative effects of $\mathrm{CPB}$, which is essential for cardiac surgery practice, for renal functions.

In the present study, we aimed to investigate the effect of duration of $\mathrm{CPB}$ on postoperative AKI in patients who underwent coronary artery bypass grafting (CABG).

\section{PATIENTS AND METHODS}

This single-center, retrospective study was conducted at Izmir Katip Celebi University, Faculty of Medicine, Department of Cardiovascular Surgery between January 2014 and January 2018. A total of 251 patients (222 males, 29 females; mean age: $61 \pm 9.4$ years; range, 37 to 88 years) who underwent elective CABG operation were included. The patients who had preoperative renal diseases and patients who were scheduled for cardiac surgery combined with CABG were excluded. The patients were divided into three groups according to $\mathrm{CPB}$ times as follows: 0 to $60 \mathrm{~min}$ (Group 1), 60 to $120 \mathrm{~min}$ (Group 2), and >120 min (Group 3). Patient's pre-, intra-, and postoperative data were recorded. Renal status of the patients was evaluated according to creatinine and eGFR levels. Acute kidney injury was defined according to the Acute Kidney Injury Network (AKIN) criteria $^{[6]}$ as follows: Stage 1, an increased postoperative creatinine level of $\geq 1.5$, but $<2$ times, compared to baseline; Stage 2, an increased postoperative creatinine level of $\geq 2$, but $<3$ times, compared to baseline; and Stage 3, an increased postoperative creatinine level of $\geq 3$ times, compared to baseline. All groups were compared according to creatinine levels. A written informed consent was obtained from each patient. The study protocol was approved by the Izmir Katip Çelebi University, Faculty of Medicine Ethics Committee (date/no: 25.04.2019/188). The study was conducted in accordance with the principles of the Declaration of Helsinki.

Baseline demographic and clinical characteristics including age, sex, body surface area, redo surgery, diabetes mellitus, hypertension, chronic obstructive lung disease, smoking, neurological dysfunction, ejection fraction, pre- and postoperative hemoglobin, white blood cell (WBC), blood urea nitrogen (BUN), creatinine, and eGFR levels were recorded. Intraoperative data including coronary bypass graft counts, $\mathrm{CPB}$ time, aortic cross-clamp time, transfusion rate, and postoperative data including mechanical ventilation time, revision, neurological complication, hemodialysis, ICU stay, in-hospital stay, and mortality rate were noted. Patient's preoperative creatinine levels were the baseline values for the calculation of eGFR. The Cockcroft-Gault formula was used to calculate eGFR (Figure 1).

\section{Statistical analysis}

Statistical analysis was performed using the IBM SPSS version 22.0 software (IBM Corp., Armonk, NY, USA). Continuous variables were expressed in mean \pm standard deviation (SD), while categorical variables were expressed in number and frequency. The Kolmogorov-Smirnov test was used to analyze the distribution of the variables. Due to the unbalanced distribution, the non-parametric tests were used. The Kruskal-Wallis and Mann-Whitney $\mathrm{U}$ test were used to analyze quantitative independent data. The Wilcoxon test was used to analyze dependent quantitative data. The chi-square test or Fisher's exact test were used to analyze qualitative independent data. A $p$ value of $<0.05$ was considered statistically significant.

\section{RESULTS}

Baseline demographic and clinical characteristics of the patients are shown in Table 1. There was no statistically significant difference among the groups in terms of age, sex, diabetes mellitus, chronic obstructive lung disease, smoking status, renal failure, hypertension, and redo surgery $(p>0.05)$. However, preoperative ejection fraction was significantly lower in Group 3 compared to Groups 1 and 2 ( $\mathrm{p}<0.05)$.

There was no statistically significant difference among the groups in terms of WBC and hemoglobin levels in the pre- and postoperative period. However, the $\mathrm{WBC}$ value increased in the postoperative period compared to the preoperative period and hemoglobin levels decreased in the postoperative period compared to baseline $(\mathrm{p}<0.05)$ (Table 2).

There was no significant difference among the groups in terms of preoperative BUN values ( $p>0.05$ ). However, the postoperative BUN values increased in

$$
\text { eGFR } \frac{(140 \text {-Age [year] } \times \text { weight }[\mathrm{kg}])}{(72)^{*} \times(\text { serumcreatinine }[\mathrm{mg} / \mathrm{dL}])}
$$

Figure 1. Cockcroft-Gault formula for eGFR calculation. eGFR: Estimated glomerular filtration rate. 


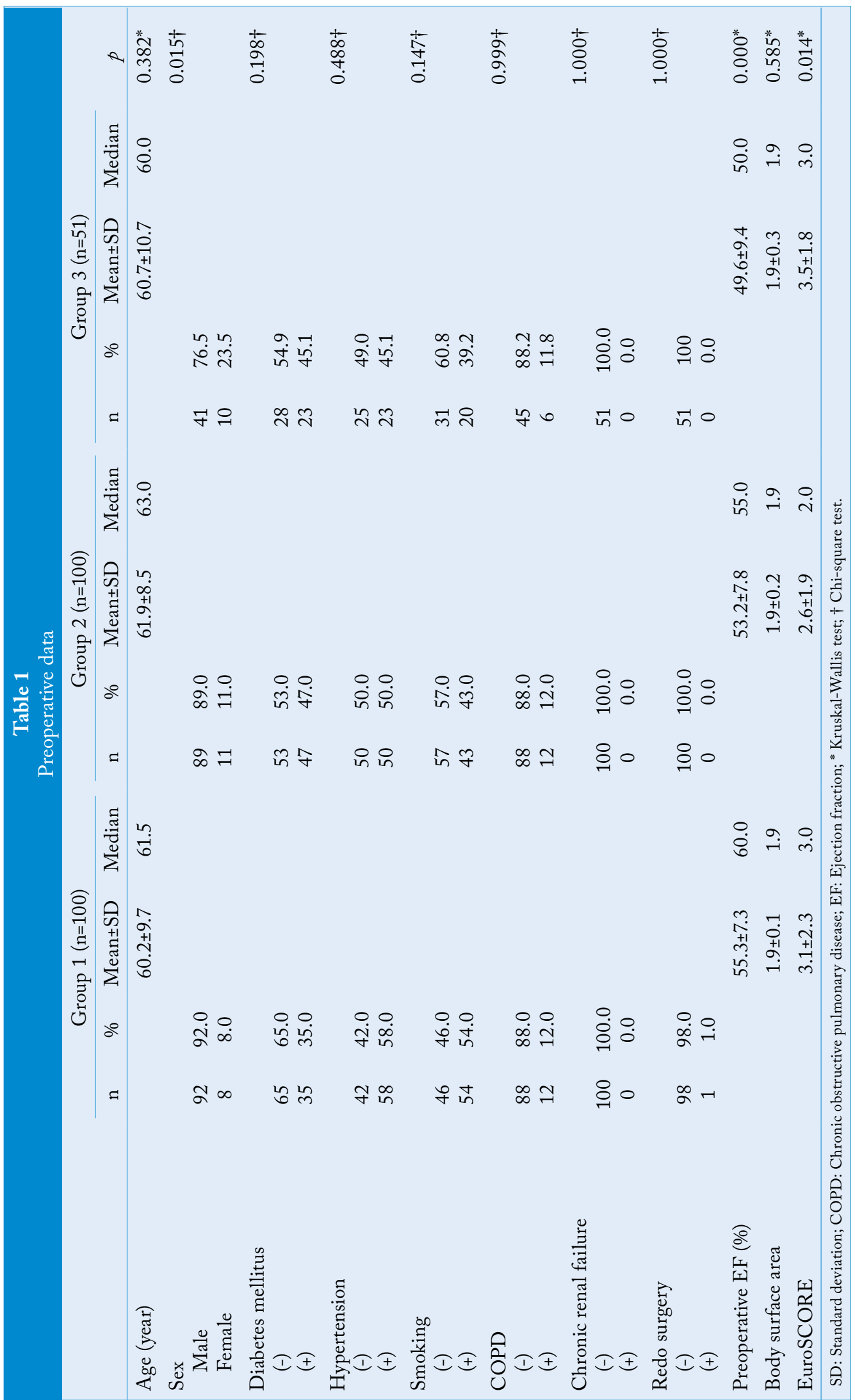




\begin{tabular}{|c|c|c|c|c|c|c|c|}
\hline & & $\begin{array}{r}\text { Table } \\
\text { aboratory }\end{array}$ & & & & & \\
\hline & Group 1 & $=100)$ & Group 2 & $=100)$ & Group 3 & $=51)$ & \\
\hline & Mean \pm SD & Median & Mean \pm SD & Median & Mean \pm SD & Median & $p^{*}$ \\
\hline Preoperative WBC $\left(\times 10^{3}\right)$ & $8.2 \pm 2.2$ & 8.0 & $7.9 \pm 2.0$ & 7.8 & $8.2 \pm 2.0$ & 7.7 & 0.506 \\
\hline Postoperative WBC $\left(\times 10^{3}\right)$ & $13.1 \pm 3.6$ & 12.8 & $13.5 \pm 4.2$ & 12.8 & $14.4 \pm 4.0$ & 13.6 & 0.149 \\
\hline$p^{\dagger}$ & 0.00 & & 0.00 & & 0.00 & & \\
\hline Preoperative hemoglobin $\left(\times 10^{3}\right)$ & $13.2 \pm 1.4$ & 13.1 & $13.1 \pm 1.5$ & 13.2 & $12.7 \pm 1.6$ & 12.9 & 0.172 \\
\hline Postoperative hemoglobin $\left(\times 10^{3}\right)$ & $9.6 \pm 1.3$ & 9.4 & $9.5 \pm 1.3$ & 9.5 & $9.2 \pm 1.2$ & 9.1 & 0.118 \\
\hline$p^{\dagger}$ & 0.00 & & 0.00 & & 0.00 & & \\
\hline Preoperative BUN & $16.3 \pm 5.3$ & 15.0 & $17.6 \pm 4.5$ & 17.0 & $17.0 \pm 6.1$ & 16.0 & 0.052 \\
\hline Postoperative BUN & $18.0 \pm 5.3$ & 17.5 & $19.9 \pm 6.7$ & 18.5 & $20.1 \pm 5.8$ & 20.0 & 0.015 \\
\hline$p^{\dagger}$ & 0.00 & & 0.00 & & 0.00 & & \\
\hline Preoperative creatinine $(\mathrm{mg} / \mathrm{dL})$ & $0.9 \pm 0.1$ & 0.82 & $0.9 \pm 0.2$ & 0.89 & $0.9 \pm 0.2$ & 0.84 & 0.057 \\
\hline Postoperative creatinine $(\mathrm{mg} / \mathrm{dL})$ & $1.0 \pm 1.0$ & 0.86 & $1.1 \pm 0.3$ & 0.97 & $1.11 \pm 0.36$ & 1.04 & 0.001 \\
\hline$p^{\dagger}$ & 0.00 & & 0.00 & & 0.00 & & \\
\hline Preoperative eGFR & $114.8 \pm 19.8$ & 118.9 & $108.2 \pm 21.1$ & 107.7 & $111.1 \pm 22.2$ & 115.5 & 0.057 \\
\hline Postoperative eGFR & $109 \pm 25.9$ & 113.1 & $96.4 \pm 33.1$ & 97.1 & $92.6 \pm 30.8$ & 89.2 & 0.001 \\
\hline$p^{\dagger}$ & 0.00 & & 0.00 & & 0.00 & & \\
\hline
\end{tabular}

SD: Standard deviation; WBC: White Blood cells; BUN: Blood urea nitrogen; eGFR: Estimated glomerular filtration rate; * Kruskal-Wallis test (Mann-Whitney U Test); † Wilcoxon Signed Rank test.

all groups compared to baseline $(\mathrm{p}<0.05)$. Postoperative BUN levels in Groups 2 and 3 were higher compared to Group $1(\mathrm{p}<0.05)$. There was no significant difference in postoperative BUN levels between Groups 2 and 3 $(\mathrm{p}>0.05)$.

Preoperative creatinine levels did not significantly differ among the groups $(p>0.05)$. However, postoperative creatinine levels increased in all groups compared to baseline $(\mathrm{p}<0.05)$. Postoperative creatinine levels were significantly higher in Groups 2 and 3, compared to Group $1(\mathrm{p}<0.05)$. There was no significant difference in postoperative creatinine levels between Groups 2 and 3 ( $p>0.05)$.

Preoperative eGFR levels did not significantly differ among the groups $(p>0.05)$. However, postoperative eGFR levels decreased in all groups compared to

\begin{tabular}{|c|c|c|c|c|c|c|c|c|c|c|c|c|c|}
\hline & & & & & & $\begin{array}{r}1 \\
\text { toper }\end{array}$ & $\begin{array}{l}\text { able } 3 \\
\text { tive AKI ra }\end{array}$ & & & & & & \\
\hline & & $\mathrm{Gr}$ & up 1 ( $n=100$ & & & & oup $2(n=100$ & & & & oup $3(n=51)$ & & \\
\hline & $\mathrm{n}$ & $\%$ & Mean \pm SD & Median & $\mathrm{n}$ & $\%$ & Mean \pm SD & Median & $\mathrm{n}$ & $\%$ & Mean \pm SD & Median & $p$ \\
\hline AKI & & & & & & & & & & & & & $0.021 \dagger$ \\
\hline$(+)$ & 4 & 4.0 & & & 10 & 10.0 & & & 9 & 17.6 & & & \\
\hline$(-)$ & 96 & 96.0 & & & 90 & 90.0 & & & 42 & 82.4 & & & \\
\hline AKI Stag & & & & & & & & & & & & & \\
\hline I & 3 & 3.0 & & & 8 & 8.0 & & & 5 & 9.8 & & & \\
\hline II & 0 & 0.0 & & & 2 & 2.0 & & & 4 & 7.8 & & & \\
\hline III & 1 & 1.0 & & & 0 & 0.0 & & & 0 & 0.0 & & & \\
\hline AKI rate & & & $1.2 \pm 1.3$ & 1.06 & & & $1.2 \pm 0.3$ & 1.09 & & & $1.2 \pm 0.3$ & 1.15 & $0.006^{*}$ \\
\hline
\end{tabular}




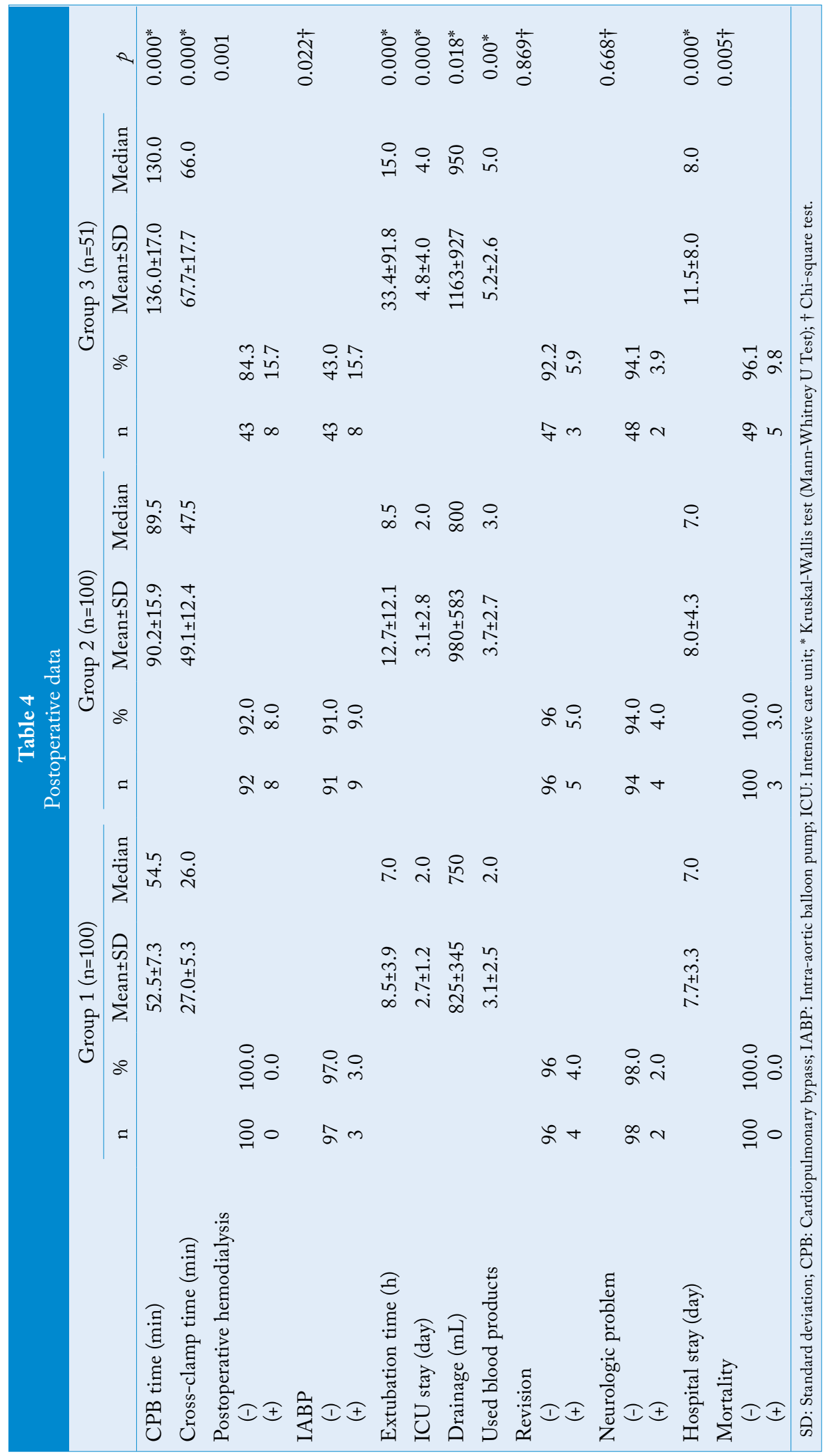


preoperative levels $(\mathrm{p}<0.05)$. Postoperative eGFR levels were significantly lower in Groups 2 and 3, compared to Group $1 \quad(p<0.05)$. There was no significant difference in postoperative eGFR levels between Groups 2 and 3 ( $p>0.05)$. Laboratory data are shown in Table 2.

The AKIN scores were significantly higher in Groups 2 and 3, compared to Group $1 \quad(p<0.05)$. However, there was no significant difference between Groups 2 and 3 in terms of the AKIN scores ( $>0.05)$ (Table 3).

The cross-clamp time and CPB time were significantly longer in Group 3 compared to Groups 1 and 2, and they were also significantly higher in Group 2 compared to Group $1(\mathrm{p}<0.05)$ (Table 4).

The number of patients requiring dialysis was higher in Groups 2 and 3, compared to Group $1(\mathrm{p}<0.05)$. There was no significant difference between Groups 2 and 3 ( $p>0.05)$. Intra-aortic balloon pump (IABP) use and mechanical ventilation time were statistically higher in Group 3, compared to Groups 1 and $2 \quad(\mathrm{p}<0.05)$. Transfusion rate, ICU stay, and in-hospital stay were also higher in Group 3, compared to Group 1 $(\mathrm{p}<0.05)$. There was no statistically significant difference between Groups 1 and 2 in terms of these parameters.

The need for drainage and revision was statistically significantly higher in Group 3, compared to Group 1 ; however, there was no significant difference between Groups 1 and 2. There was no significant difference among the groups in terms of neurological complications $(p>0.05)$. However, the mortality rate was higher in Group 3, compared to Group $1(\mathrm{p}<0.05)$, although there was no significant difference between Groups 1 and 2 (Table 4).

\section{DISCUSSION}

With the aging population, the prevalence of coronary artery disease has been increasing all around the world recently. As the aging population increases, the number of CABG operations also increases. ${ }^{[7]}$ The CABG is still the gold-standard technique for the treatment of coronary artery disease. Mortality rate varies between 2.5 and $26 \%{ }^{[7]}$ Renal damage is a frequent complication after $\mathrm{CABG}$ and is usually seen as a mild creatinine increase. However, in some cases, creatinine increase may be high or AKI may complicate prognosis in patients with high comorbidities, leading to the increased mortality. ${ }^{[8]}$

Hemodialysis need after cardiac surgery ranges between 1 and 7\%. Mortality rate in patients with renal failure is $60 \% \cdot{ }^{[9,10]}$ There is also the increased rate of infection and prolonged hospital stay in patients who have CPB-related AKI. ${ }^{[1]}$ Therefore, postoperative renal dysfunction is an important complication due to its relation with postoperative mortality and morbidity. ${ }^{[12,13]}$ The main causes of CPB-related AKI are decreased perfusion pressure, nephrotoxic agents, and CPB-related inflammatory response. ${ }^{[14-16]}$ The main goal of $\mathrm{CPB}$ is to maintain tissue perfusion. Perfusionist regulates this process by coordinating the mean arterial pressure and $\mathrm{CPB}$ flow rate.

Extracorporeal circulation with $\mathrm{CPB}$ produces systemic inflammatory response. As the $\mathrm{CPB}$ time increases, the risk of systemic inflammatory response syndrome (SIRS) also increases. ${ }^{[17]}$ There are many studies showing that a CPB time longer than $80 \mathrm{~min}$ poses a significant risk for SIRS. ${ }^{[18]}$ Review of the literature also reveals that there is a relation between $\mathrm{AKI}$ and $\mathrm{CPB}$, as described previously before a relation between CBP and SIRS. Zhiwei et al. ${ }^{[19]}$ concluded that prolonged perfusion time was related to AKIN Stage $\geq 2$ renal damage and it was a major risk factor for postoperative AKI. In our study, we analyzed patients according to $\mathrm{CPB}$ time. We showed that the increased CPB time was strongly related to AKI as follows: Group 1, 4\% $(n=4)$; Group 2, 10\% $(\mathrm{n}=10)$, and Group 3, 17.6\% $(\mathrm{n}=9)$. The AKIN scores were higher in Groups 2 and 3, compared to Group 1 $(\mathrm{p}<0.05)$. We found that one (1\%) patient in Group 1, two (2\%) patients in Group 2, and four (7.8\%) patients in Group 3 had AKIN $\geq$ Stage 2, respectively.

In another study including acute renal failure patients after cardiac surgery, Bove et al. ${ }^{[12]}$ included 5,068 patients and they found that 171 patients had AKI after cardiac surgery. In addition, 94 patients needed renal replacement therapy and patients who needed renal replacement therapy had a longer mean CPB time $(116 \pm 51.2 \mathrm{~min})$ compared to those who did not $(82 \pm 31.7)$. They concluded that decreased CPB time also decreased the CPB-related AKI. In our study, 16 patients needed postoperative hemodialysis (Group 2, n=8, 8\%; Group 3, n=8, 15.7\%). The need for hemodialysis was significantly higher in Groups 2 and 3, compared to Group 1; however, there was no statistically significant difference between 
Groups 2 and 3. The main goal of the intraoperative patient management in terms of $\mathrm{CPB}$ is to manage optimal perfusion pressure, flow rate, hemodilution, and $\mathrm{CPB}$ time. Therefore, managing $\mathrm{CPB}$ time in an appropriate level would reduce the AKI risk, postoperative morbidity, and mortality. ${ }^{[20]}$

In a study by Elmanday et al., ${ }^{[21]} \mathrm{CPB}$ time had a statistically significant importance for the development of postoperative AKI. They found that postoperative creatinine and BUN levels were significantly higher and eGFR levels were significantly lower in the AKI group, compared to non-AKI group. In our study, there was no significant difference in the preoperative creatinine, BUN, and eGFR values. However, postoperative creatinine and BUN levels were higher in Groups 2 and 3, compared to Group 1. Also, the eGFR levels were significantly lower in Groups 2 and 3, compared to Group 1. Perioperative anemia is another important indicator of postoperative AKI. ${ }^{[22,23]}$ In our study, we showed that there was no statistically significant difference in the hemoglobin levels among the groups.

Patients with left ventricular dysfunction have an increased AKI risk. ${ }^{[22]}$ Low cardiac output and the need for inotropic or mechanical support after cardiac surgery are also major risk factors for AKI. ${ }^{[22]}$ In our study, three (3\%) patients in Group 1, nine (9\%) patients in Group 2, and eight (15.7\%) patients in Group 3 needed IABP. The need for IABP in Group 3 was significantly higher, compared to Group 1. Ortega-Loubon et al. ${ }^{[2]}$ performed a study about AKI-related ICU stay and mortality after CABG in 435 patients. The mean ICU stay for their patients with and without AKI was $7.4 \pm 9.3$ days and $2.7 \pm 2.2$ days, respectively. The 30 -day mortality rate was $18.5 \%$ and $3.1 \%$ in patients with and without AKI, respectively. In our study, we found that the ICU stay and in-hospital stay were higher in Group 3, compared to the other groups. There was no significant difference between Groups 1 and 2. The mortality rate in Group 3 was significantly higher compared to Group 1. In the literature, there is a limited number of studies regarding AKI and neurological complications after cardiac surgery. A study by Ryden et al. ${ }^{[25]}$ showed that postoperative neurological complication in patients with AKI were higher compared to those without postoperative AKI. In our study, there was no significant difference among the groups ( $\mathrm{p}>0.05)$.
The main limitations of this study include its single-center, retrospective design with a relatively small sample size. In addition, only creatinine and eGFR values were used for the AKIN classification; however, there are many other sensitive parameters such as renal-specific proteins to calculate renal function and eGFR. Screening of the risk factors along with the measurement of novel biomarkers may enable early diagnosis of patients who are susceptible to AKI and may be helpful to tailor the appropriate treatment protocol.

In conclusion, the incidence of CPB-related AKI is still high in our surgical practice. The most important way to reduce the risk of CPB-related AKI is to manage the modifiable risk factors for patients and extracorporeal circulation technique. It is a good option to prefer off-pump techniques for patients who have a high postoperative AKI risk. Furthermore, decreasing the inflammatory response and $\mathrm{CPB}$ time for on-pump procedures may also contribute to prevent AKI.

\section{Declaration of conflicting interests}

The authors declared no conflicts of interest with respect to the authorship and/or publication of this article.

\section{Funding}

The authors received no financial support for the research and/or authorship of this article.

\section{REFERENCES}

1. Brodie JE, Johnson RB, editors. The manual of clinical perfusion. 2nd ed. Augusta, GA: Glendale Medical Corporation; 1994. Çeviri editörleri: Zeybek R, İşkesen İ. Klinik Perfüzyon El Kitabı. Manisa: Meta Basım; 1999.

2. Bilgili B, Haliloğlu M, Cinel İ. Sepsis ve akut böbrek hasarı. Turk J Anaesth Reanim 2014;42:294-301.

3. Alkan Bozkaya $\mathrm{T}$. Kalp cerrahisi sonrasında organ hasarının erken belirteçleri olarak biyo-belirteçler. JOHESAM 2015;5:65-74.

4. Özhan A, Akgül E, Parlar Aİ, Çekirdekçi A. The association of blood transfusion and acute kidney injury in diabetic coronary artery bypass grafting patients. Cardiovasc Surg Int 2021;8:13-9.

5. Kaul TK, Swaminathan R, Chatrath RR, Watson DA. Vasoactive pressure hormones during and after cardiopulmonary bypass. Int J Artif Organs 1990;13:293-9.

6. Mehta RL, Kellum JA, Shah SV, Molitoris BA, Ronco C, Warnock DG, et al. Acute Kidney Injury Network: report of an initiative to improve outcomes in acute kidney injury. Crit Care 2007;11:R31. 
7. ElBardissi AW, Aranki SF, Sheng S, O'Brien SM, Greenberg CC, Gammie JS. Trends in isolated coronary artery bypass grafting: An analysis of the Society of Thoracic Surgeons adult cardiac surgery database. J Thorac Cardiovasc Surg 2012;143:273-81.

8. Lee JH, Murrell HK, Strony J, Cmolik B, Nair R, Lesnefsky $\mathrm{E}$, et al. Risk analysis of coronary bypass surgery after acute myocardial infarction. Surgery 1997;122:675-80.

9. Uchino S, Bellomo R, Bagshaw SM, Goldsmith D. Transient azotaemia is associated with a high risk of death in hospitalized patients. Nephrol Dial Transplant 2010;25:1833-9.

10. Unal E, Ozen A, Boysan E, Tak S, Basar V, Turkcan B, et al. Serum interleukin-18 as an early marker of acute kidney injury following open heart surgery. Turk Gogus Kalp Dama 2014;22:483-8.

11. Tuttle KR, Worrall NK, Dahlstrom LR, Nandagopal R, Kausz AT, Davis CL. Predictors of ARF after cardiac surgical procedures. Am J Kidney Dis 2003;41:76-83.

12. Bove T, Calabrò MG, Landoni G, Aletti G, Marino G, Crescenzi G, et al. The incidence and risk of acute renal failure after cardiac surgery. J Cardiothorac Vasc Anesth 2004;18:442-5.

13. Thakar CV, Yared JP, Worley S, Cotman K, Paganini EP. Renal dysfunction and serious infections after open-heart surgery. Kidney Int 2003;64:239-46.

14. Han SS, Shin N, Baek SH, Ahn SY, Kim DK, Kim S, et al. Effects of acute kidney injury and chronic kidney disease on long-term mortality after coronary artery bypass grafting. Am Heart J 2015;169:419-25.

15. Karkouti K, Wijeysundera DN, Yau TM, Callum JL, Cheng DC, Crowther M, et al. Acute kidney injury after cardiac surgery: Focus on modifiable risk factors. Circulation 2009;119:495-502.

16. Okusa MD. The inflammatory cascade in acute ischemic renal failure. Nephron 2002;90:133-8.
17. Hirai S. Systemic inflammatory response syndrome after cardiac surgery under cardiopulmonary bypass. Ann Thorac Cardiovasc Surg 2003;9:365-70.

18. Whitten CW, Hill GE, Ivy R, Greilich PE, Lipton JM. Does the duration of cardiopulmonary bypass or aortic cross-clamp, in the absence of blood and/or blood product administration, influence the IL- 6 response to cardiac surgery? Anesth Analg 1998;86:28-33.

19. Li Z, Fan G, Zheng X, Gong X, Chen T, Liu X, et al. Risk factors and clinical significance of acute kidney injury after on-pump or off-pump coronary artery bypass grafting: A propensity score-matched study. Interact Cardiovasc Thorac Surg 2019;28:893-9.

20. Kumar AB, Suneja M. Cardiopulmonary bypass-associated acute kidney injury. Anesthesiology 2011;114:964-70.

21. Elmedany SM, Naga SS, Elsharkawy R, Mahrous RS, Elnaggar AI. Novel urinary biomarkers and the early detection of acute kidney injury after open cardiac surgeries. J Crit Care 2017;40:171-7.

22. Parida S, Badhe AS. Cardiac surgery-associated acute kidney injury. J Anesth 2013;27:433-46.

23. Karkouti K, Grocott HP, Hall R, Jessen ME, Kruger C, Lerner $\mathrm{AB}$, et al. Interrelationship of preoperative anemia, intraoperative anemia, and red blood cell transfusion as potentially modifiable risk factors for acute kidney injury in cardiac surgery: A historical multicentre cohort study. Can J Anaesth 2015;62:377-84.

24. Ortega-Loubon C, Fernández-Molina M, PañedaDelgado L, Jorge-Monjas P, Carrascal Y. Predictors of postoperative acute kidney injury after coronary artery bypass graft surgery. Braz J Cardiovasc Surg 2018;33:323-9.

25. Rydén L, Ahnve S, Bell M, Hammar N, Ivert T, Holzmann MJ. Acute kidney injury following coronary artery bypass grafting: Early mortality and postoperative complications. Scand Cardiovasc J 2012;46:114-20. 